\title{
Seabed sediment volume computations using single beam echo sounder with dual frequencies based on different interpolation methods
}

\section{Taylan Ocalan}

Department of Geomatic Engineering, Faculty of Civil Engineering, Yildiz Technical University, Davutpasa Campus, 34220, Istanbul, Turkey.

Accepted 28 June, 2018

\begin{abstract}
This study aims to examine and compare the interpolation methods under different grid sizes used for terrain modelling in order to compute the seabed sediment volume accurately. For this purpose, the single beam data was collected from an ELAC 4300 Hydrographic echo sounder dual frequency 200 and $30 \mathrm{kHz}$. A case study was conducted at Gulf of Gemlik, located in the south of Sea of Marmara. The depth in the survey area varies between 1 and $24 \mathrm{~m}$. The total survey area covers $0.5 \mathrm{~km}^{2}$. Besides investigating the effects of the interpolation methods preferred on this study, the grid size effect is also considered under varying regular grid intervals as $0.5,1.0,2.0,4.0$ and $10 \mathrm{~m}$. The selection of the appropriate model is done depending on the RMSEs values of the sea floor surface. At this stage, cross-validation procedure is implemented. To compute the sediment layer thickness and volumes, three volume calculations namely, Trapezoidal Rule, Simpson's Rule and Simpson's 3/8 Rule, are used. According to the results, it can be concluded that Radial Basis Interpolation method with varying 0.5 and $4.0 \mathrm{~m}$ grid sizes gives lower RMSE values. According to this, the Simpson's Rule volume computation provides accurate sediment layer volume.
\end{abstract}

Keywords: Seabed, sediment layer, interpolation methods, bathymetrical data, single beam echo sounder (SBES), volume.

E-mail: tocalan@yildiz.edu.tr, taylantnt@yahoo.com.

\section{INTRODUCTION}

Specifications about the marine environment should be understood accurately to carry out several studies on marine life such as about marine geology and biology and coastal engineering applications. Among them, shallow-water environment is required to known well especially for evaluating the acoustic propagation with respect to consideration of sonar performance characteristics (Siemes et al., 2010). Accurately generated seafloor topography for several marine and marine related activities such as marine geology, commercial fishing, offshore oil prospecting and drilling, cable and pipeline laying and maintenance, and underwater warfare, may be ensured by tools and methods, which are remotely controlled (Hellequin et al., 2003). Among these tools and methods, acoustic remotely sensing techniques represent effective and efficient solutions in terms of capacity of coverage and budget considering collecting sample data of the seafloor for seabed characterization (Siemes et al., 2010). In addition to this, for navigation and security purposes, shallow coastal areas should be assessed more carefully (Bannari and Kadhem, 2017). Coastal areas are important in global ecosystem biodiversity to provide sustainability and reduce the damages for potential risks that can be caused by storms, floods and sea level rise (Burke et al., 2011). Single beam echo sounders (SBES) 
collect bathymetric soundings by measuring the elapsed time for measuring the depth to the sea with an acoustic pulse that travels between a generating transducer to the waterway bottom and back. Travelling time of the pulse generated from a transducer that measured by echo sounders is converted to the water depth. The sending signals and the reflected acoustic signals from the sea floor are recorded at the transducer. The depth is calculated from the two-way-travel-time of the velocity of sound in water.

For several marine based studies, sedimentation and its distribution should be determined accurately before working on sediment removal (Simpson and $\mathrm{Wu}, 2014$ ) related to the construction matters. To determine the sedimentation, bathymetrical surveys with low and high frequencies allow estimating the thickness of sediment layer. High frequency acoustic data penetrate upper layer of the seafloor. Nevertheless, although low frequency sounders have lower resolution than high frequency acoustic data, they are able to operate in larger ranges, thus penetrate deeper layers of seafloor (Deimling et al., 2013). Besides that, low-frequency seismic systems (e.g. $20 \mathrm{kHz}$ ) provide details about sediment layering (Siemes et al., 2010). To measure the thickness of the sediment layer and accurately compute the volume, the bathymetric data collected with low frequency acoustic generates the sub-bottom sea surface since there is an ability to penetrate into the seafloor. To provide the sea floor, high frequency acoustic data are used to generate the sea floor.

A digital elevation model defines the surface mathematically, usually determined for points of a regular area wide grid, applying a specific interpolation method to a set of selected uniform or non-uniform samples available within the study area ( $\mathrm{Li}$ et al., 2004). Digital elevation models (DEMs) have been widely used for hydrological analyses and modelling (Liu et al., 2017). The accuracy of a digital elevation model mainly depends on the quality, density, and distribution of the selected samples within the study area as well as on the mathematical model applied for interpolation of samples (Tunalioglu, 2012). Once the appropriate method on surface modelling is estimated, then the sediment layer thickness and consequently the volume of it may be estimated accurately. As stated Simpson and Wu (2014), evaluations of interpolation including sediment data are rarely studied.

In this study, we aim to examine and compare the interpolation methods under different grid sizes used for terrain modelling in order to compute the seabed sediment volume accurately. For this purpose, the single beam data was collected with dual frequency at Gulf of Gemlik, located in the south of Sea of Marmara. The collected bathymetrical data are then processed to generate the sea floor and sub sea floor. The volume of sediment layer is computed by subtracting the surface models using three different volume computations.

\section{MATERIALS AND METHODS}

\section{Study area and site survey}

The study area is located in Gemlik Gulf, southern of The Marmara Sea, Turkey (Figure 1). The single beam data was collected from an ELAC 4300 Hydrographic echo sounder. All data was collected from a small vessel on $2012,8^{\text {th }}$ July. The weather was partly sunny and the temperature during the survey was $31^{\circ} \mathrm{C}$. The study area was surveyed with dual frequency; a $200 \mathrm{kHz}$ and a 30 $\mathrm{kHz}$ single beam echo sounder (SBES).

The area surveyed by SBES is indicated by the red colored dots in Figure 2. The total survey area covers 0.5 $\mathrm{km}^{2}$ and the depth inside the boarder varies between 1 and 24 meters. The dataset of the survey included 6829 geo-referenced elevation points. An Aschtech ProMark 500 GPS geodetic receiver in Real-Time Kinematic (RTK) mode was used. The accuracy is $10 \mathrm{~mm} \pm 1.00 \mathrm{ppm}$ horizontal and $20 \mathrm{~mm} \pm 1.00 \mathrm{ppm}$ vertical. The datum is WGS84, Central Meridian $30^{\circ}$. The raw data collected by the survey is scattered $x, y, z$ format. The survey with 30 $\mathrm{kHz}$ computed deeper depths than the survey with 200 $\mathrm{kHz}$ data. This observation provides the penetration of the low frequency signal energy into soft sediments (Deimling et al., 2013). The determination of the salinity was performed by RBRconcerto CTD. The salinity is calculated by measuring the conductivity and temperature of the water, which also made enable of computing density anomaly and speed of sound.

\section{METHODOLOGY}

The bathymetric data collected with dual frequency were processed using four interpolation methods: 1) Kriging 2) Minimum Curvature 3) Triangulated Irregular Network (TIN) and 4) Radial Basis Function, to generate a threedimensional sea floor surface (bottom topography) and sub bottom surface models. As stated in Li et al. (2004), interpolation is a mathematical function to model the surfaces or terrains digitally, which includes several stages of processing to ensure quality control, surface reconstruction, accuracy assessment, terrain analysis, and applications. Moreover, Simpson and Wu (2014) reviewed that interpolation techniques have been used for several environmental studies such as rainfall (Willmott et al., 1985; Jeffrey et al., 2001), wind velocity and air temperatures (Jarvis and Stuart, 2001) and evapotranspiration studies (Willmott, 1982) and others. The distribution and density of the source data, interpolation method to be selected for modelling and grid interval can be listed as the major factors that highly affect the accuracy of the terrain model (Gong et al., 2000; Kienzle, 2004; Li et al., 2004; Liu et al., 2007).

There are various techniques for $3 \mathrm{D}$ visualization of the surveyed data on digital terrain/surface models. Among 


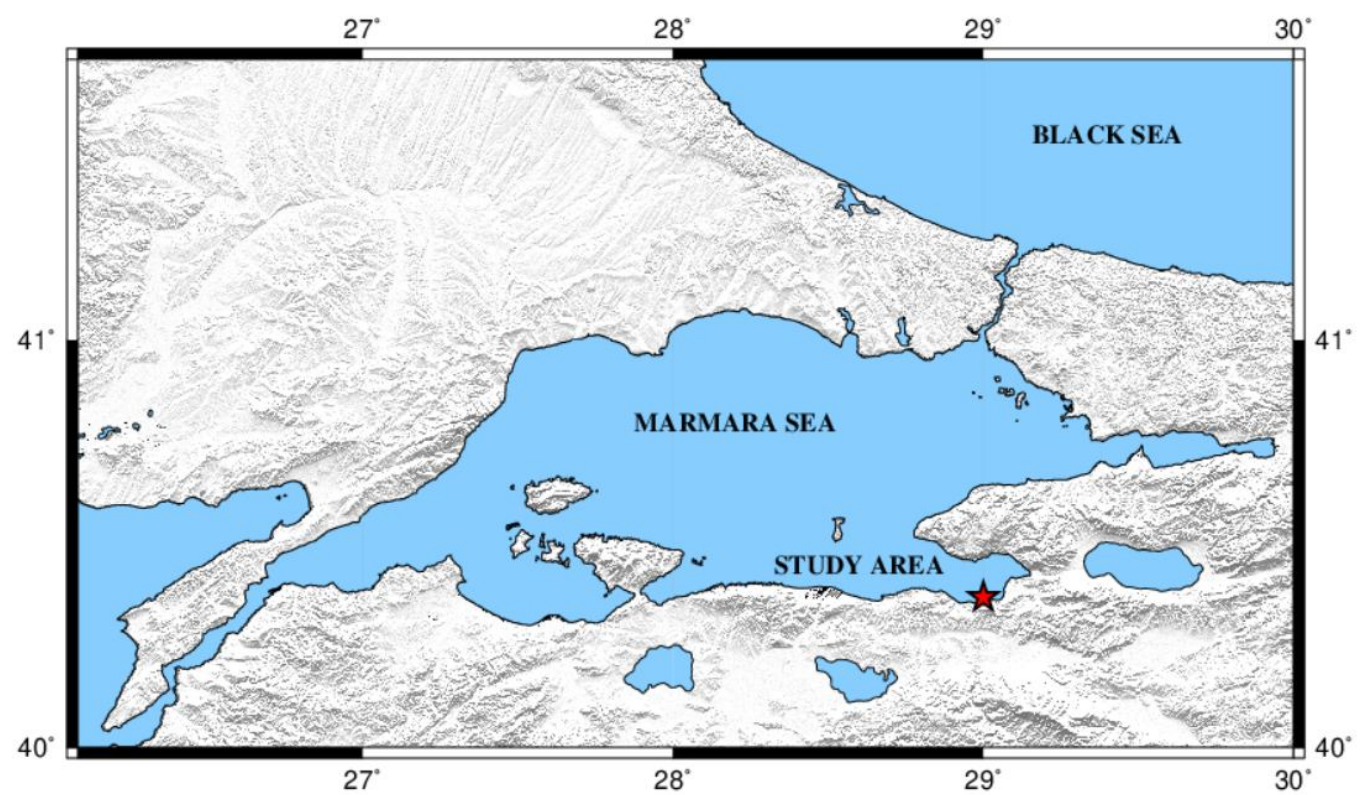

Figure 1. Location map of study area (red star indicates the area of interest).

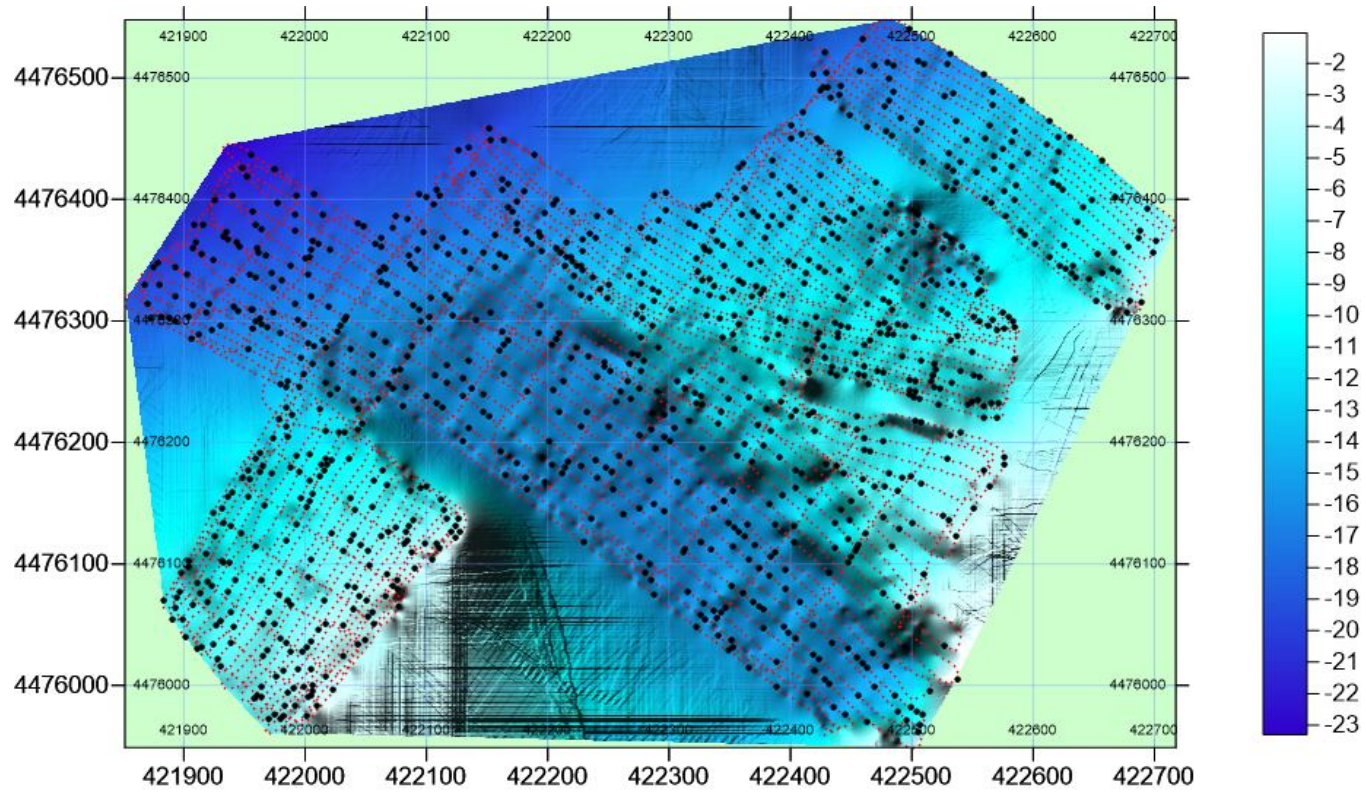

Figure 2. The survey area with track lines: Kriging Interpolation Method used for Regular Spacing for Gridding 0.5 meter, red dots: data points black dots: cross validation points- represented using bottom data points.

them, the most commonly used forms of representing data is the grid and TIN (Triangulated Irregular Networks). In this study, the varying regular-spaced grids were created to analyze the accuracy assessment of the generated surfaces.

In this study, the accuracy of the models and the results were analyzed for the given interpolation methods using cross-validation procedure. The differences between interpolated and known height values of the reference points were calculated and standard deviations computed from the interpolated and known heights of the surface models were used for assessing the quality of the interpolations (Tunalioglu, 2012). Error analysis was performed on the generated grids by comparing them with raw data. The cross-validation procedure was implemented to the DEMs by 1000 reference validation 
points selected from the datasets. A root mean square error (RMSE) analysis from validations was used to assess how well the models fit the data. Equation 1 gives the formula of RMSE:

$R M S E=\sqrt{\frac{1}{n} \sum_{i=1}^{n}\left(Z_{i}^{1}-Z_{i}\right)^{2}}$

where, $\mathrm{n}$ is the data point estimated, $\mathrm{Z}^{\prime}$ is the estimated depth value from interpolation method, $\mathrm{Z}$ is the depth of the control point.

Here, sea-floor surface was taken into consideration by means of lower RMSEs to decide the accurate volume computations. To compute the thickness of the sediment layer and volumes, sub bottom surface was subtracted from the sea floor surface. At the last stage, the volume of the sediment layer is computed based on three volume calculations, namely Trapezoid, Simpson' Rule and Simpson's 3/8 Rule methods (Yilmaz, 2017).

\section{RESULTS}

To perform analysis, the bathymetric data was gridded and modelled with the mentioned interpolation methods and the statistical information for minimum, maximum and root mean square error (RMSE) of differences between the interpolated and known data points were computed. Table 1 shows the statistical information of the implemented methods under different grid intervals.

When we consider the variations of grid intervals respect to the models used; Radial Basis Function (RBF) estimates the lowest RMSE values as 0.0967, 0.0968, $0.0968,0.0973$ and $0.1288 \mathrm{~m}$ for each grid intervals, respectively (Figure 3 ). The RMSEs change slightly up to $10.0 \mathrm{~m}$ grid interval and $0.1288 \mathrm{~m}$ of RMSE is computed at $10.0 \mathrm{~m}$ grid interval. When comparing the other three interpolation methods for grid intervals $0.5,1.0$ and 2.0 $\mathrm{m}$, the highest RMSEs are estimated by Triangulation with Linear Interpolation Method as 0.1208, 0.1198 and $0.1171 \mathrm{~m}$, respectively. The RMSE for $4.0 \mathrm{~m}$ grid interval is slightly close to the smaller grid intervals and for the variation of RMSE may be mentioned for $10.0 \mathrm{~m}$ grid interval as $0.1532 \mathrm{~m}$ similar to the RBF results. Since the Kriging and Minimum Curvature analysis provide similar RMSE values, the Minimum Curvature method estimates the lower RMSEs of $0.5,1.0$ and $2.0 \mathrm{~m}$ grid intervals as $0.1073,0.1028$ and $0.1055 \mathrm{~m}$, respectively than Kriging method. For the grid intervals equal and higher than 4.0 $\mathrm{m}(4.0$ and $10.0 \mathrm{~m})$, Kriging interpolation method estimates lower RMSEs as 0.1104 and $0.1391 \mathrm{~m}$, respectively. According to the results of cross validation, the sea floor surface model derived from the RBF model with $0.5 \mathrm{~m}$ grid size was taken as reference in terms of lower RMSE value estimated. This enables to compare computations of sediment layer volumes accurately.

The volumes of the sedimentation layer were computed with three computation procedures by subtracting the modelled surfaces from sub bottom to sea floor (Table 2). Depending on the statistical results estimated from the bathymetrical data collected from sea floor (Table 1) and to be able to compare the volume computations depending on the computation procedure and due to the close results of the volumes of sediment layer for RBF surface generation with $0.5 \mathrm{~m}$ grid size, the volume computed by RBF with $0.5 \mathrm{~m}$ grid interval is taken as reference for each volume computation procedure and graphical representation of the volume variations are given in Figure 4.

To compare the volume computation methods, the RBF modelling with $0.5 \mathrm{~m}$ grid size is also taken as references for each volume computations. According to Table 3, the closest volume values to the reference were computed from Simpson's 3/8 Rule. The absolute volumes vary between 5.21 and $133.26 \mathrm{~m}^{3}$ for RBF interpolation. The volume differences for Trapezoidal Rule and Simpson's Rule vary between 1.33 and $447.14 \mathrm{~m}^{3} ; 1.05$ and 276.44 $\mathrm{m}^{3}$, respectively. The maximum volume differences were obtained for grid interval $10 \mathrm{~m}$, which also has the highest RMSE values (Table 1). However, the volumes computed from the other interpolation methods show large differences when compared with the reference model. The highest absolute differences for sediment layer volume are computed for Minimum Curvature, Triangulation with Linear Interpolation and Kriging, respectively for each grid size.

\section{CONCLUSIONS}

Bathymetric data is essential for several marine applications such as seafloor mapping, monitoring the underwater habitat, the ecological life and tectonic activities, offshore construction, underwater cable laying etc., which all studies require accurate modelling and interpretation. The data collected by dual frequency provides not only sea floor surface data but also enables to extract sub bottom information of a survey area, which gives the possibility to create very detailed digital elevation model of them. In this study, interpolation methods with different grid intervals were examined for sediment layer thickness to estimate and determine the accurate sedimentation layer volume.

As mentioned, for various marine and marine related studies, sedimentation and its distribution should be determined accurately to make an accurate planning on the study area for several studies such as construction facilities, removal works, marine geology, commercial fishing, offshore oil prospecting and drilling, cable and pipeline laying and maintenance, underwater warfare etc. Bathymetrical surveys with low and high frequencies allow estimating the thickness of sediment layer and consequently calculation of sediment layer volumes. Although high frequency acoustic data offer low seafloor 
Table 1. Statistical results determined with the interpolation models for sea floor of Gemlik Gulf.

\begin{tabular}{|c|c|c|c|c|}
\hline & Kriging & Minimum curvature & Triangulation with linear int. & Radial basis function \\
\hline \multicolumn{5}{|c|}{ Grid Interval $=0.5 \mathrm{~m}$} \\
\hline Min. (m) & -0.7990 & -0.8130 & -0.9193 & -0.6343 \\
\hline Max. (m) & 0.4302 & 0.4190 & 0.6787 & 0.3750 \\
\hline RMSE (m) & 0.1075 & 0.1073 & 0.1208 & 0.0967 \\
\hline \multicolumn{5}{|c|}{ Grid Interval $=1.0 \mathrm{~m}$} \\
\hline Min. (m) & -0.8013 & -0.7965 & -0.9193 & -0.6337 \\
\hline $\operatorname{Max} .(\mathrm{m})$ & 0.4306 & 0.3854 & 0.6802 & 0.3759 \\
\hline RMSE (m) & 0.1078 & 0.1028 & 0.1198 & 0.0968 \\
\hline \multicolumn{5}{|c|}{ Grid Interval = $2.0 \mathrm{~m}$} \\
\hline Min. (m) & -0.8060 & -0.7939 & -0.9193 & -0.6354 \\
\hline $\operatorname{Max} .(\mathrm{m})$ & 0.4315 & 0.3141 & 0.6898 & 0.3773 \\
\hline RMSE (m) & 0.1083 & 0.1055 & 0.1171 & 0.0968 \\
\hline \multicolumn{5}{|c|}{ Grid Interval $=4.0 \mathrm{~m}$} \\
\hline Min. (m) & -0.8236 & -0.9006 & -0.9481 & -0.6393 \\
\hline $\operatorname{Max} .(\mathrm{m})$ & 0.4849 & 0.4802 & 0.7089 & 0.3875 \\
\hline RMSE (m) & 0.1104 & 0.1190 & 0.1183 & 0.0973 \\
\hline \multicolumn{5}{|c|}{ Grid Interval $=10.0 \mathrm{~m}$} \\
\hline Min. (m) & -1.0746 & -1.1001 & -1.0937 & -0.9823 \\
\hline Max. (m) & 0.7764 & 0.9365 & 1.0892 & 0.5205 \\
\hline RMSE (m) & 0.1391 & 0.1606 & 0.1532 & 0.1288 \\
\hline
\end{tabular}

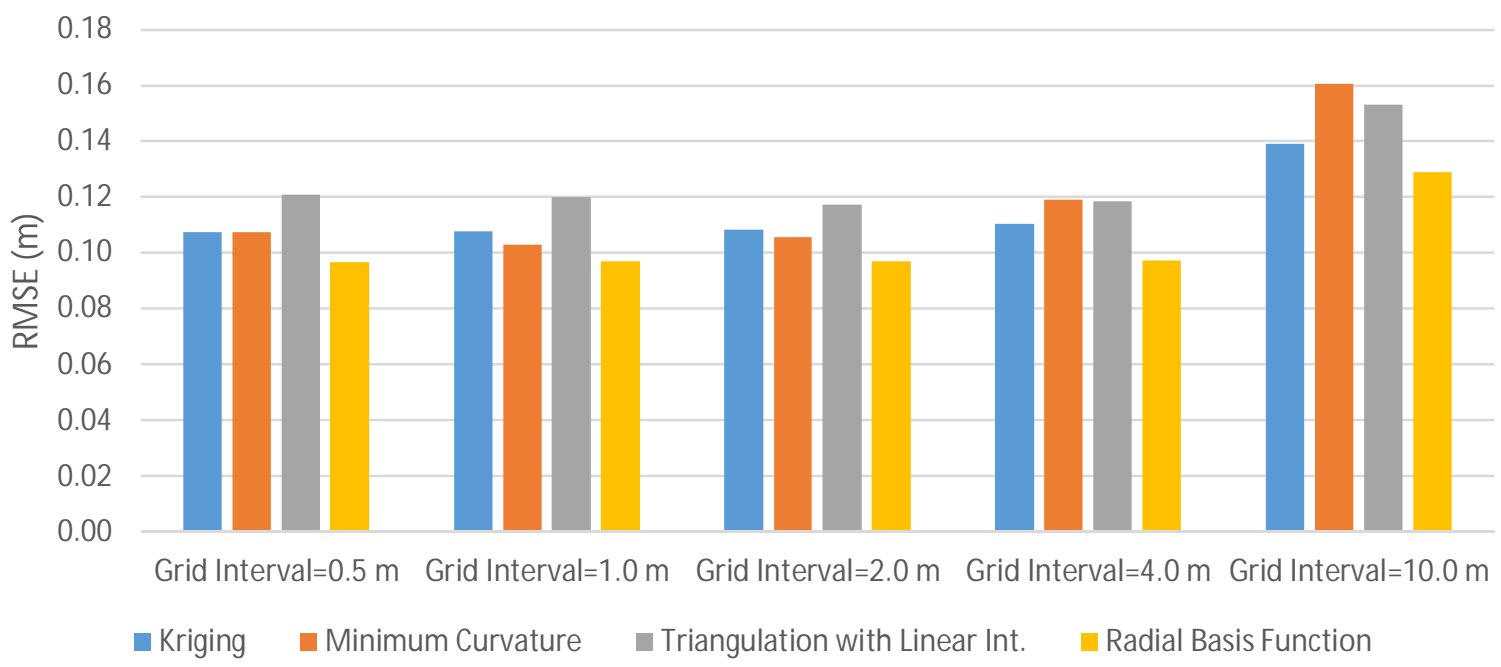

Figure 3. RMSE values under different grid intervals.

penetration, low frequency sounders have lower resolution but allow greater operating ranges to penetrate deeper seafloor. If the study area gets larger, the volume variations will play a critical role on planning activities.

In this study, it is aimed to examine and compare the interpolation methods under different grid sizes used for terrain modelling in order to compute the seabed sediment volume accurately. According to the statistical results, RBF provides the accurate digital elevation model for small grid size. We use this information to generate the sediment layer and compare the volume computations. Three volume computations, namely 
Table 2. Volumes of sediment layer.

\begin{tabular}{|c|c|c|c|c|c|}
\hline Parameter & $\begin{array}{c}\text { Grid interval } \\
(\mathrm{m})\end{array}$ & Kriging & $\begin{array}{l}\text { Minimum } \\
\text { curvature } \\
\end{array}$ & $\begin{array}{l}\text { Triangulation with } \\
\text { linear }\end{array}$ & Radial basis function \\
\hline \multirow{4}{*}{ Trapezoid $\left(\mathrm{m}^{3}\right)$} & 0.5 & 200048.1826 & 201603.6880 & 199710.3947 & 200275.7297 \\
\hline & 1.0 & 200041.9389 & 201346.2731 & 199705.9919 & 200269.4827 \\
\hline & 4.0 & 199997.9360 & 201451.9296 & 199666.3354 & 200223.7220 \\
\hline & 10.0 & 199607.6805 & 200722.7516 & 199262.9646 & 199828.5886 \\
\hline \multirow{4}{*}{ Simpson's Rule $\left(\mathrm{m}^{3}\right)$} & 1.0 & 200039.8277 & 201343.7052 & 199703.2039 & 200266.7586 \\
\hline & 2.0 & 200050.8148 & 201342.0631 & 199711.3698 & 200278.4925 \\
\hline & 4.0 & 200092.9350 & 201546.4663 & 199764.5092 & 200313.5929 \\
\hline & 10.0 & 199785.3283 & 200911.0582 & 199423.2882 & 200001.0053 \\
\hline \multirow{2}{*}{$\begin{array}{l}\text { Simpson's 3/8 Rule } \\
\left(\mathrm{m}^{3}\right)\end{array}$} & 4.0 & 200042.8539 & 201490.2278 & 199706.1894 & 200271.4369 \\
\hline & 10.0 & 199926.6813 & 201002.3459 & 199578.9792 & 200143.7091 \\
\hline
\end{tabular}
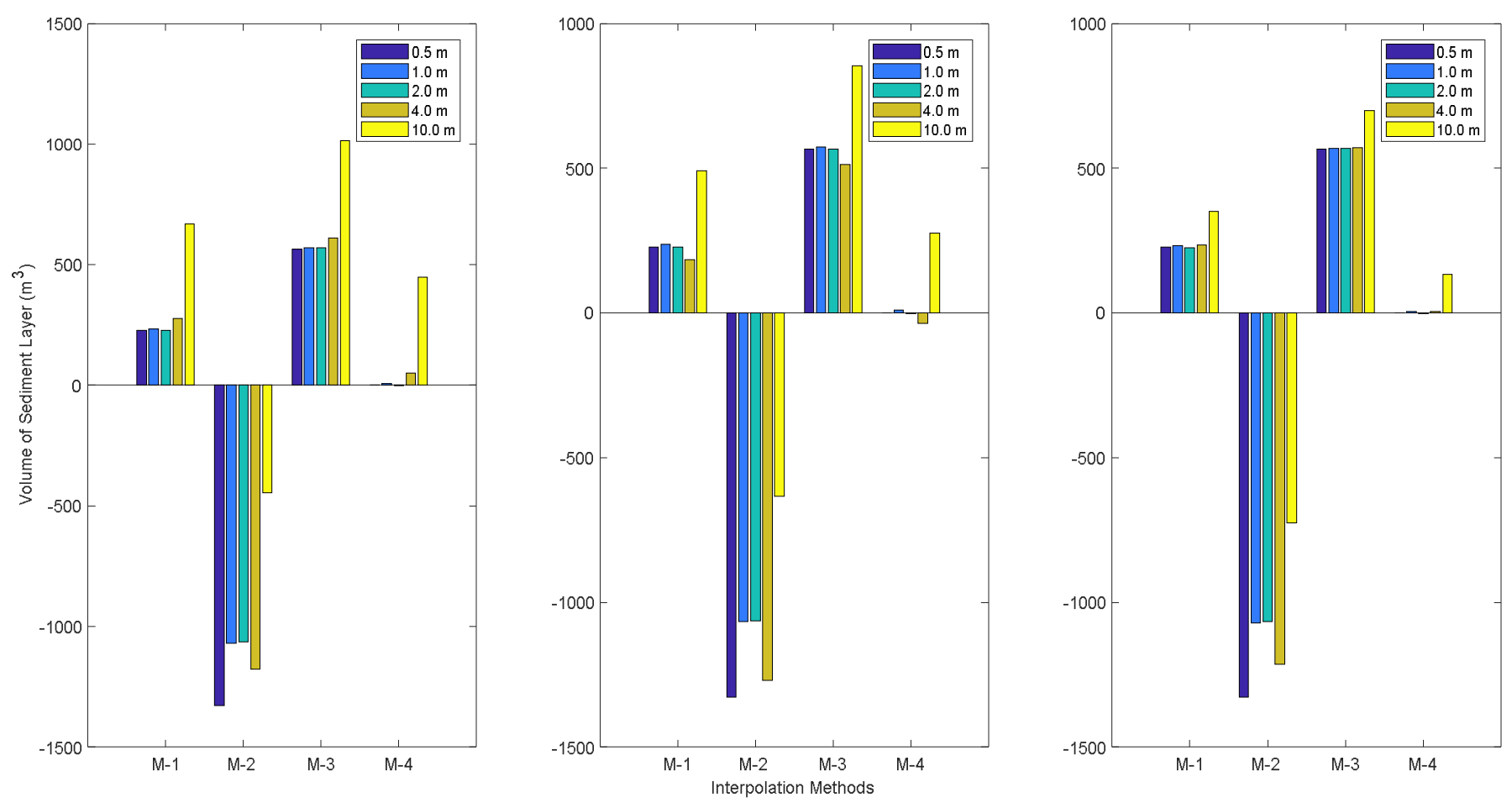

Figure 4. The graphical representation of volume differences of sediment layers (as the reference volume is taken RBF $0.5 \mathrm{~m}$ grid interval; $M-1,2,3,4$ refer to the interpolation methods with respect to the Table $2,1^{\text {st }}$ row).

Trapezoidal Rule, Simpson's Rule and Simpson's 3/8 Rule were compared by using the accurate sea floor and sub bottom surfaces generated by RBF. It can be concluded that Simpson's 3/8 Rule computes more accurate sediment layer volume under varying grid intervals tested in this study. 
Table 3. Volume differences of sediment layer.

\begin{tabular}{lccccc}
\hline Parameter & $\begin{array}{c}\text { Grid interval } \\
(\mathbf{m})\end{array}$ & Kriging & Minimum curvature & Triangulation with linear & Radial basis function \\
\hline & 0.5 & 227.5471 & -1327.9583 & 565.3350 & 0.0000 \\
Trapezoid & 1.0 & 233.7908 & -1070.5434 & 569.7378 & 6.2470 \\
$\left(\mathrm{~m}^{3}\right)$ & 2.0 & 227.0744 & -1063.2968 & 568.7637 & -1.3399 \\
& 4.0 & 277.7937 & -1176.1999 & 609.3943 & 52.0077 \\
& 10.0 & 668.0492 & -447.0219 & 1012.7651 & 447.1411 \\
& & & & & \\
& 0.5 & 227.4709 & -1327.4021 & 565.8018 & 0.0000 \\
Simpson's Rule & 1.0 & 237.6127 & -1066.2648 & 574.2365 & 10.6818 \\
$\left(\mathrm{~m}^{3}\right)$ & 2.0 & 226.6256 & -1064.6227 & 566.0706 & -1.0521 \\
& 4.0 & 184.5054 & -1269.0259 & 512.9312 & -36.1525 \\
& 10.0 & 492.1121 & -633.6178 & 854.1522 & 276.4351 \\
& & & & & \\
& 0.5 & 227.6574 & -1327.7440 & 565.5511 & 0.0000 \\
Simpson's 3/8 Rule & 1.0 & 232.9855 & -1072.2944 & 567.8943 & 5.2139 \\
$\left(\mathrm{~m}^{3}\right)$ & 2.0 & 225.7647 & -1065.1568 & 569.2986 & -1.9724 \\
& 4.0 & 234.1108 & -1213.2631 & 570.7753 & 5.5278 \\
& 10.0 & 350.2834 & -725.3812 & 697.9855 & 133.2556 \\
\hline
\end{tabular}

\section{ACKNOWLEDGEMENT}

The authors would like to thank the MARINMET Company for conducting field work of this study and for their valuable supports.

\section{REFERENCES}

Bannari A, Kadhem G, 2017. MBES-CARIS Data validation for bathymetric mapping of shallow water in the Kingdom of Bahrain on the Arabian Gulf. Remote Sens, 9: 385.

Burke L, Reytar K, Spalding M, Perry A, 2011. Reefs at Risk Revisited. World Resources Institute: Washington, DC, USA, p. 230.

Deimling JS, Weinrebe W, Tóth Zs, Fossing H, Endler R, Rehder G, Spieß V, 2013. A low frequency multibeam assessment: Spatial mapping of shallow gas by enhanced penetration and angular response anomaly. Marine Petroleum Geol, 44: 217-222.

Gong J, Li Z, Sui H, Zhou Y, 2000. Effects of various factors on the accuracy of DEM: an intensive experimental investigation. Photogrammetric Engineering and Remote Sensing, 66(9): 11131117.

Hellequin L, Boucher JM, Lurton X, 2003. Processing of high-frequency multibeam echo sounder data for seafloor characterization. IEEE $\mathrm{J}$ Ocean Eng, 28(1): 78-89.

Jarvis $\mathrm{CH}$, Stuart $\mathrm{N}$, 2001. A comparison among strategies for interpolating maximum and minimum daily air temperatures, Part II: The Interaction between number of guiding variables and type of interpolation method. Am Meteorol Soc, 40: 1075-1084.

Jeffrey SJ, Carter JO, Moodie KB, Beswick AR, 2001. Using spatial interpolation to construct a comprehensive archive of Australian climate data. Environ Monit Softw, 16: 309-330.

Kienzle S, 2004. The effect of DEM raster resolution on first order, second order and compound terrain derivatives. Transactions in GIS, 8: 83-111

Li Z, Zhu Q, Gold C, 2004. Digital Terrain Modeling- Principles and Methodology. $3^{\text {rd }}$ ed.; CRC Press, Florida.
Liu X, Wang N, Shao J, Chu X, 2017. An automated processing algorithm for flat areas resulting from DEM filling and interpolation. ISPRS Int J Geo-Inf, 6: 376.

Liu X, Zhang Z, Peterson J, Chandra S, 2007. The effect of Lidar data density on DEM accuracy, Proceedings of the International Congress on Modelling and Simulation (MODSIM07), Christchurch, New Zealand.

Siemes K, Snellen M, Amiri-Simkooei AR, Simons DG, Hermand JP, 2010. Predicting Spatial Variability of Sediment Properties From Hydrographic Data for Geoacoustic Inversion. IEEE Journal of Oceanic Engineering, 35(4): 766-778.

Simpson $G$, Wu $Y H, 2014$. Accuracy and effort of interpolation and sampling: Can GIS help lower field costs? ISPRS Int J Geo-Inf, 3: 1317-1333.

Tunalioglu N, 2012. Quality test of interpolation methods on steepness regions for the use in surface modelling. Tehnički vjesnik, 19(3): 501507

Willmott CJ, 1982. Some comments on the evaluation of model performance. Bull Am Meteorol Soc, 63: 1309-1313.

Willmott CJ, Ackleson SG, Davis RE, Feddema JJ, Klink KM, Legates DR, O'Donnell J, Rowe CM, 1985. Statistics for the evaluation and comparison of models. J Geophys Res, 90: 8995-9005.

Yilmaz N, 2017. Comparing the volume methods through using digital elevation models created by different interpolation methods. Fresenius Environ Bull, 26(7): 4734-4741.

Citation: Ocalan T, 2018. Seabed sediment volume computations using single beam echo sounder with dual frequencies based on different interpolation methods. Afr J Eng Res, 6(2): 32-38. 